Original Contribution

\title{
VIRUS SHEDDING IN CO-INFECTIONS OF LOW PATHOGENIC AVIAN INFLUENZA VIRUS (H6N2) AND LENTOGENIC NEWCASTLE DISEASE VIRUS (LA SOTA) IN NUMIDA MELEAGRIS
}

\author{
Iv. Zarkov*, Al. Valchev \\ Department of Microbiology, Infectious and Parasitic Diseases, Faculty of Veterinary Medicine, \\ Trakia University, Stara Zagora, Bulgaria
}

\begin{abstract}
An experiment was conducted to evaluate the effect of a low-pathogenic H6N2 avian influenza A viral strain (LPAIV strain H6N2) on subsequent (after 3 days) vaccination with a lentogenic avian paramyxovirus serotype 1 strain La Sota (APMV-1 strain La Sota) in guinea fowl. The effects were monitored by detection of the presence of viruses in cloacal and oropharyngeal samples, as well as by the presence of humoral immune response. The obtained results were compared to birds with monoinfections. Replication and virus shedding of LPAIV strain H6N2 from the cloaca and the oropharynx were established, while APMV-1 La Sota was reisolated only from the oropharynx. The reisolation of LPAIV strain H6N2 was similar in both monoinfection and co-infection. The dynamics of virus replication of APMV-1 strain La Sota was affected in the beginning of the co-infection, later occurrence of the peak which matched the period of decline of LPAIV strain H6N2 reisolates. The LPAIV strain H6N2 and APMV-1 strain La Sota co-infection did not exert any influence on humoral immune response to both viruses.
\end{abstract}

Key words: Numida meleagris, Influenza A virus, Newcastle disease virus, Co-infections.

\section{INTRODUCTION}

Depending on the number of microorganisms involved in infections, they are divided into monoinfections and mixed (co-infections). In the former, only one pathogen is responsible while more than one pathogens are involved in co-infections.

Investigations in co-infections have focused on the combined effects of pathogens on host health, the diagnostic approached for differentiation of infectious agents, the interrelationships of both pathogens.

In birds, co-infections with different pathogens have been studied - with two viruses, as well as with viruses and bacteria.

Shortridge and King (1) demonstrated that several AIV subtypes (H4N6, H5N3, H7N2, H9N2, H12N5) and co-infection with APMV-1 resulted in preferential detection of AIV in comparison to APMV-1. The causes were attributed by authors to the different replication

\footnotetext{
*Correspondence to: Ivan Zarkov, Department of Microbiology, Infectious and Parasitic diseases, Faculty of Veterinary Medicine, Trakia University, Stara Zagora, Bulgaria, E-mail: ivan_zarkov@abv.bg
}

of the two viruses and the their inherent interference. The results of Liu et al. (2) showed that AIV (with H9) interfered strongly with APMV-1 replication of infected CE, which was influenced by the presence of serum containing antibodies. Ge et al. (3) have studied co-infection with two AIV strains (F98 and H5N1) and two APMV-1 strain (LaSota and F48E8) in CE through real-time RT-PCR. Various variants of co-infection were tested: preliminary infection with AIV followed by APMV-1 and vice versa, the second virus being inoculated after 12 or 24 hours. The experiments proved that when various doses of AIV and APMV-1 were applied at the same time, AIV had a negative effect on APMV-1 replication. The Newcastle disease virus did not influence AIV replication. The extent of influence on APMV-1 at equivalent viral amounts depended on the time of inoculation of the second virus and AIV virulence. The AIV replication was influenced only when CE were first infected with APMV-1.

The overview of literature revealed interference in CE co-infected with AIV and APMV-1 using both classical and modern methods. The results were dependent on the viral dose, time of inoculation of the second 
virus, the virulence of strains and the presence of antibodies.

Co-infections with two viruses in birds are often seen in the field, but little information about them is available so far. Concomitant infection could exacerbate the course of the disease, leading to mixed clinical signs, increased mortality and pathological findings could differ from the usual ones (4). What is more, co-infection with two viruses could alter their tropism and hence, to erroneous diagnosis $(1,5)$.

Infection with both low-pathogenic AIV (LPAIV) strains and lentogenic APMV-1 is different from infections caused by either of viruses. It is due to the fact that AIV and APMV-1 have the same receptors and the same localisation in the body (respiratory and digestive tracts) because of their dependence on trypsin and trypsin-like enzymes. There, they compete for target cells and as a result, co-infection, depending on avian species, could entail a change in virus progeny with effects on clinical signs, immune response and thus, renders the detection in poultry flocks more difficult (6). Examples could be found in the studies of El Zowalaty et al. (7); CostaHurtado et al. (8); França et al. (9) and Sajid Umar et al. (10).

El Zowalaty et al. (7) showed that mixed infection with APMV-1 and AIV (detected by RT-PCR) in cloacal sample of free-range ducks could inhibit AIV replication and yield negative results from attempts for its isolation in CE (false negative results). The processing of cloacal samples with sera containing anti APMV-1 antibodies made AIV isolation possible.

Costa-Hurtado et al. (8) infected chickens and turkeys with a lentogenic APMV-1 strain LaSota and LPAIV subtype H7N2 either independently, simultaneously and successively. Chickens did not exhibit clinical signs of disease in neither case. There were differences in virus shedding, comprising lower titres of the second virus on the $2^{\text {nd }}$ and $3^{\text {rd }}$ day post infection, evidencing altered propagation dynamics. The turkeys infected with LPAIV or co-infected with lentogenic APMV-1 strain showed mild clinical signs of disease. The differences related to the number of infected birds and viral titres were higher.

França et al. (9) made an experiment with onemonth-old mallards infected intranasally and simultaneously with a lentogenic APMV-1 strain and a LPAIV (H3N8) and another experiment with LPAIV (H3N8) applied 2 and 5 days after the lentogenic APMV-1 strain. The results showed that all birds were infected with both viruses as seen from virus shedding and serological response to the two pathogens. There was no statistically significant difference between cloacal samples in the favour of LPAIV. The authors concluded that the coinfection with APMV-1 did not influence LPAIV replication in mallards.

Sajid Umar et al. (10) obtained results similar to those of Costa-Hurtado et al. (8) in Egyptian fayoumi chickens. A part of the birds were infected intranasally with one virus only, and another part - at the same time with a lentogenic APMV-1 strain and LPAIV H9N2. For the first three days from the beginning of co-infection, lower titres and lower amounts of both viruses were detected as compared to monoinfections. In the next days, the amount of LPAIV H9N2 in the oropharynx increased while that of APMV-1 remained low.

El-Yuguda et al. $(11,12)$ conducted trials with guinea fowl and chickens. In two experiments with guinea fowl, they investigated the immune response after vaccination with live infectious bursal disease virus (IBDV) vaccine followed by vaccination with a lentogenic $\mathrm{La}$ Sota APMV-1 seven days later. The second experimental design was the same only a pathogenic IBDV strain was used. The authors reported disturbances in the humoral immune response in both bird species when the vaccinal APMV-1 virus was applied later. It was present both when vaccinal or pathogenic IBDV were used. The impaired humoral immunity was attributed by the authors to the necrosis in lymphoid organs induced by the infectious bursal disease virus.

No studies are reported about monoinfections and co-infections in guinea fowl with LPAIV and APMV-1. The aim of the present study was to elucidate the effects of LPAIV challenge on the subsequent vaccinated with APMV-1in guinea fowl.

\section{MATERIAL AND METHODS VIRUSES AND INOCULUM PREPARATION}

Viruses. A low-pathogenic AIV H6N2 (A/duck/Bulgaria/05) isolate from a wild duck Anas plathyrynchos (13) was used. For vaccination of birds against Newcastle disease, a lentogenic La Sota APMV-1 strain was used (CEVAC ${ }^{\circledR}$ NEW $L$ contains the La Sota lentogenic strain of Newcastle Disease virus in live, freeze-dried form). Before APMV-1 
cultivation, the lyophilised strain was reconstituted with $1 \mathrm{ml}$ sterile distilled water.

Chick embryos were used for maintenance of viruses. Four 9 day-old CE were infected with $0.2 \mathrm{ml}$ viral suspensions in the allantoic cavity. Infected $\mathrm{CE}$ was incubated at $37^{\circ} \mathrm{C}$ for 4 days. $\mathrm{CE}$ was opened and the allantoic fluid was collected in sterile flasks. The allantoic fluid was used in the haemagglutination (HA) test with $1 \%$ chicken red blood cells. Influenza viruses with haemagglutination titre 1:256 and APMV-1 with haemagglutination titre 1:2048 were stored at $-80^{\circ} \mathrm{C}$ until used.

Viral titres were determined by the method of Reed \& Muench (14) in chick embryos inoculated in the allantoic cavity at $0.1 \mathrm{ml}$. The 50 percent embryo infectious dose $\left(\mathrm{EID}_{50}\right)$ was then determined.

\section{BIRDS AND PROTOCOL DESIGN}

Birds. Twenty guineafowl at 5 months of age were hatched in our Department and reared in isolated premises. Six of them were infected with LPAIV strain H6N2, another 6 vaccinated with APMV-1 strain La Sota. Six birds were infected with LPAIV strain H6N2 and two days later, vaccinated with APMV-1 La Sota. Two birds were used as controls and were inoculated with allantoic fluid of noninfected 9 day-old CE. The infection was performed with viral isolate H6N2 (A/Bulgaria/ Anas Plathyrynchos/2006) with titre $10^{5.0} \mathrm{EID}_{50} / 0.1 \mathrm{ml}(0.2 \mathrm{ml}$ intranasally and $0.2 \mathrm{ml}$ orally). The vaccination was performed with APMV-1 (strain La Sota) with titre $10^{9.4}$ $\mathrm{EID}_{50} / 0.1 \mathrm{ml}(0.2 \mathrm{ml}$ intranasally and $0.2 \mathrm{ml}$ orally).

The different groups of birds were housed in separate premises $\left(4 \times 4 \mathrm{~m}^{2}\right)$ with feeding and drinking width of $1.8 \mathrm{~m}$, at ambient temperature $20{ }^{\circ} \mathrm{C}$ and humidity $70 \%$.

Samples. Cloacal and oropharyngeal samples were obtained from all experimental birds in order to reisolated the virus. Samples were collected from the $1^{\text {st }}$ to the $12^{\text {th }}$ day from infected and vaccinated birds. The total number of samples from infected and vaccinated birds was 432 (half cloacal; half oropharyngeal). From the non-infected population, a total of 48 samples were obtained, including from the day zero.

Blood samples were collected on days 14, 21 and 28 from the beginning of the experiment.

VIRUSES RE-ISOLATION AND IDENTIFICATION

A. Virus reisolation in chick embryos (CE). CE was obtained from clinically healthy
DeKalb hens. They were hatched in our facilities, reared in an isolated premise, nonvaccinated and with serologically negative for antibodies (Ab) against AIV, NDV, APMV-2.

- Preparation of samples for CE inoculation. Samples for virus isolation were obtained with sterile cotton swabs in MEM transport medium supplemented with $0.5 \%$ foetal bovine calf serum (FBS) and antibiotics: Penicillin G $\left(2 \times 10^{6} \mathrm{U} / \mathrm{L}\right), \quad$ Streptomycin $(200 \mathrm{mg} / \mathrm{L})$, Polymyxin B $\left(2 \times 10^{6} \mathrm{U} / \mathrm{L}\right)$, Gentamicin sulfate $(250 \mathrm{mg} / \mathrm{L})$, Nystatin dihydrate $\left(0.5 \times 10^{6} \mathrm{U} / \mathrm{L}\right)$, Sulfamethoxazole $(0.2 \mathrm{~g} / \mathrm{L})$. The $\mathrm{pH}$ was corrected to 7.2-7.4. The medium was added to samples in an amount needed to obtain $10 \%$ suspension. After centrifugation at $2000 \mathrm{rpm}$ for $20 \mathrm{~min}$, the supernatant was used for CE inoculation. In order to reisolate the viruses, each sample was inoculated in three 9 day-old CE (Anonymous, OIE, 2012, 2015). Inoculated $\mathrm{CE}$ was daily monitored by an otoscope until the $5^{\text {th }}$ day $\left(120^{\text {th }}\right.$ hour $)$. The CE dead before the $5^{\text {th }}$ day and all $\mathrm{CE}$ on the $5^{\text {th }}$ day were cooled for 2 hours at $4{ }^{0} \mathrm{C}$ and allantoic fluids were collected.

Bacteriological control was performed at the time of allantoic fluid collection in grape sugar agar.

- Detection of haemagglutinating virus. The presence of haemagglutinating isolated was detected with microhaemagglutination assay (MHA) at room temperature $\left(22{ }^{\circ} \mathrm{C}-25{ }^{\circ} \mathrm{C}\right)$ and reading of the result after 15-20 min (when controls were ready). For this purpose, we prepared a series of two-fold dilutions of allantoic fluid $(0.05 \mathrm{ml})$ in sterile phosphate buffered solutions from 1:2 to 1:4096. To the diluted allantoic fluid, $0.05 \mathrm{ml} 1 \%$ suspension of chicken erythrocytes was added. The highest dilution of allantoic fluid with lack of agglutinated red blood cells was indicative for the presence of haemagglutinating virus, whereas the last dilution without agglutinated erythrocytes determined the titre of viral haemagglutinins $(15,16)$. The last dilution without agglutinated erythrocytes contained one unit viral haemagglutinin (1 HAU).

\section{B. Detection of haemagglutinin type of} reisolates as $\mathrm{H6}$ of AIV or APMV-1.

For this test, haemagglutinating antigen of the unknown viral reisolate had to be standardized and subtype-specific monospecific haemagglutinins (MSHA) raised against $\mathrm{H} 6$ of AIV or APMV-1 had to be present.

- Obtaining subtype-specific monospecific sera from the AIV A/duck/Bulgaria/05 H6N2 isolate and from APMV-1. 
Three experimental chickens were inoculated intravenously and subcutaneously with allantoic fluids from viral strains maintained in CE. Adjuvants were supplemented in case of s.c. application (incomplete and Freund's adjuvant - NIIPD, No 1150185, No 6924). The protocol was run as followed:

- Day 1, i.v. inoculation of 3 chickens with 1 $\mathrm{ml}$ of each viral strain.

- Day 14, s.c. inoculation with $2 \mathrm{ml} \mathrm{1:1}$ mixture of viral strain and complete Freund's adjuvant.

- After 14 days (day 28) blood samples were collected for test of haemagglutinin levels and in case of satisfactory results - another 2 weeks later (day 42), the birds were completely bled.

Experiments were compliant to humane practices as per Ordinance 25/10.06.2003 of the Ministry of Agriculture and Food. All infected birds were euthanized by cervical dislocation (art 20, p. 1, Annex 4, B).

\section{- Microhaemagglutination assay protocol for subtyping of reisolates and blood serum antibodies.}

The performance of the assay and reading of results was done with known antibodies (MSHA) and for antibody detection - with known antigens (AIV strain H6N2; APMV-1 strain La Sota) as described in Anonymous, OIE, 2012, $2015(15,16)$.

\section{RESULTS}

\section{Virus titration}

Viral titres were determined by the presence of positive haemagglutination in allantoic fluid
(Zarkov, 2007). Embryo infectious dose (EID) of both viruses - influence A virus H6N2 (A/duck/Bulgaria/05/ H6N2) and APMV-1 La Sota were calculated. The titre of AIV H6N2 (A/duck/Bulgaria/05/ H6N2) were $10^{5.00} / \mathrm{EID}_{50}$ $/ 0.1 \mathrm{ml}$, and that of APMV-1strain La Sota: $10^{9.46} / \mathrm{EID}_{50} / 0.1 \mathrm{ml}$.

\section{Obtained monospecific haemagglutinins.}

The results of chickens inoculated with two antigen types: that of influenza A virus H6N2 (A/duck/Bulgaria/05/H6N2) and APMV-1 strain La Sota demonstrated that available antihaemagglutinins in chickens challenged with AIV H6N2 (A/duck/Bulgaria/05/ H6N2) against 4 HAU influenza A virus H6N2 (A/duck/Bulgaria/05/ H6N2) were with titre 1:512, while against the APMV-1 La Sota strain was lower than the initial dilution <1:2. Antihaemagglutinins in chickens inoculated with strain La Sota of APMV-1 against 4 HAU APMV-1 strain La Sota had a titre 1:1024, and against AIV H6N2 (A/duck/Bulgaria/05/ H6N2) was lower than the first dilution <1:2. According to the results, obtained MSHA had antibodies only against the viruses, with which birds have been inoculated and could be used for determination of the type of unknown reisolates - influenza A virus $\mathrm{H} 6 \mathrm{~N} 2$ and APMV-1.

\section{Virus reisolation}

Data are presented in Table 1. Positive oropharyngeal samples against both viruses were obtained in the three populations. Among cloacal samples, only populations challenged with H6N2 $\left(2^{\text {nd }}\right.$ and $\left.3^{\text {rd }}\right)$ were positive.

Table 1. Results from reisolation and differentiation of viruses like APMV-1 and/or H6N2 AIV from three populations - birds vaccinated only with APMV-1 strain La Sota, infected only with AIV strain H6N2, infected with AIV strain H6N2 and after 2 days, vaccinated with APMV-1 strain La Sota

\begin{tabular}{|c|c|c|c|c|c|c|c|c|c|c|c|c|c|c|}
\hline $\begin{array}{l}\text { Reisolates, by days } \\
\quad \downarrow\end{array}$ & & & 1 & 2 & $\begin{array}{l}3 / \\
1\end{array}$ & $\begin{array}{l}4 / \\
2\end{array}$ & $\begin{array}{l}5 / \\
3\end{array}$ & $\begin{array}{l}6 / \\
4\end{array}$ & $\begin{array}{l}7 / \\
5\end{array}$ & $\begin{array}{l}8 / \\
6\end{array}$ & $\begin{array}{l}91 \\
7\end{array}$ & $\begin{array}{l}10 / \\
8\end{array}$ & $\begin{array}{l}\text { Total } \\
\text { isolates }\end{array}$ & $\begin{array}{l}\text { Mean } \\
\text { period }\end{array}$ \\
\hline \multirow{2}{*}{\multicolumn{2}{|c|}{$\begin{array}{l}\text { From vaccinated only } \\
\text { with APMV-1(first } \\
\text { population) }\end{array}$}} & $\mathrm{C}^{*}$ & - & - & 0 & 0 & 0 & 0 & 0 & 0 & 0 & 0 & $\mathbf{0}$ & 0 \\
\hline & & $\mathbf{O}^{* *}$ & - & - & 4 & 6 & 6 & 6 & 0 & 0 & 0 & 0 & 22 & 2.64 \\
\hline \multirow{4}{*}{$\begin{array}{l}\text { Infected with AIV } \\
\text { and } 2 \text { days later } \\
\text { vaccinated with } \\
\text { APMV-1 (second } \\
\text { population) }\end{array}$} & \multirow{2}{*}{ APMV-1 } & $\mathbf{C}$ & - & $* * *$ & 0 & 0 & 0 & 0 & 0 & 0 & 0 & 0 & 0 & 0 \\
\hline & & $\mathbf{O}$ & - & - & 4 & 3 & 6 & 6 & 5 & 1 & 0 & 0 & 23 & \begin{tabular}{|l|l|}
3.61 \\
\end{tabular} \\
\hline & \multirow[t]{2}{*}{ AIV } & $\mathbf{C}$ & 6 & 6 & 5 & 6 & 5 & 4 & 3 & 1 & 1 & 1 & 37 & $\mathbf{3 . 9 5}$ \\
\hline & & $\mathbf{O}$ & 6 & 6 & 6 & 5 & 4 & 3 & 2 & 0 & 0 & 0 & 32 & 3.38 \\
\hline \multirow{2}{*}{\multicolumn{2}{|c|}{$\begin{array}{l}\text { Infected with AIV (third } \\
\text { population) }\end{array}$}} & C & 6 & 6 & 6 & 6 & 6 & 5 & 3 & 2 & 1 & 1 & 42 & 4.19 \\
\hline & & 0 & 6 & 6 & 6 & 5 & \begin{tabular}{|l|}
3 \\
\end{tabular} & 2 & 1 & 1 & 0 & 0 & 30 & $\begin{array}{l}3.27 \\
\end{array}$ \\
\hline
\end{tabular}

In the population vaccinated against APMV-1, reisolates from or pharyngeal samples were present until the $4^{\text {th }}$ post vaccination day, and in the population infected only with AIV H6N2 - twice longer (until the $8^{\text {th }}$ day). In the second population (co-infection), reisolates of 
the La Sota strain were detected until post vaccination day 6 ( 2 days more than the group vaccinated only against APMV-1). In coinfected population, the reisolates were by $50 \%$ less than the population which was only vaccinated. The H6N2 на AIV was reisolated until the $7^{\text {th }}$ day.

The reisolates of APMV-1 strain La Sota were similar for both populations (22 and 23 for the $1^{\text {st }}$ and $2^{\text {nd }}$ population). The difference was $4.35 \%$. The reisolates of AIV H6N2 were 30 for the $3^{\text {rd. }}$ population and 32 for the $2^{\text {nd }}$ one (by $6.25 \%$ more in co-infected birds). The most prolonged reisolated (in days) was observed for APMV-1 La Sota in the population with co-infection (3.61 days). Then followed AIV H6N2 reisolates in the same population (3.38 days). On the third and fourth place were reisolates from birds with monoinfection (3.27 days for AIV H6N2 and 2.64 days for APMV-1 strain La Sota).

From cloacal swabs, only AIV H6N2 was reisolated. The time of reisolation was the same for populations with mono- and coinfection (10 days). More reisolates were found in the population with monoinfection (42), than in that with co-infection (37 or by $11.9 \%$ less). These results influenced the mean reisolation times: 4.19 days for monoinfection and 3.95 days for co-infection.

\section{Antibody detection}

There were no antibodies against Influenza A virus strain H6N2 and APMV-1 strain La Sota in tested blood sera from the non-infected population of guinea fowl

All birds from the $1^{\text {st }}$ and $3^{\text {rd }}$ population had antibodies, as well as against H6N2 from the $2^{\text {nd }}$ population. The test for $\mathrm{Ab}$ against APMV1 gave positive results in $94.44 \%$ birds from the second population (one bird was negative on the $14^{\text {th }}$ day). Antibody titres ranged from $1: 8$ to $1: 256$. The highest MAT was observed on the $14^{\text {th }}$ day, followed by the $21^{\text {st }}$ and $28^{\text {th }}$ day.

The MAT results from the 3 populations were compared in Table 2. In all tests, higher MAT was present on the $14^{\text {th }}$ day. A significant difference in the results by days was found out on the $21^{\text {st }}$ day against APMV-1. In the first population (vaccinated against APMV-1) MAT was 1:32, while in those infected with AIV followed by vaccination against APMV-1: considerably lower $(1: 18)$. By the $28^{\text {th }}$ day, difference was also observed, yet less significant. By the $14^{\text {th }}$ day, the $2^{\text {nd }}$ and the $3^{\text {rd }}$ populations yielded the same results against AIV. There were differences by the $21^{\text {st }}$ and the $28^{\text {th }}$ day. Higher MAT was present in the birds from the second compared to the third population. The summarised MAT result in all populations demonstrated highest titres against AIV from the $2^{\text {nd }}$ population $(1: 42.67)$, followed by antibodies against APMV-1 from the $1^{\text {st }}$ population $(1: 36)$, third came the $3^{\text {rd }}$ population with antibodies against AIV (1:33.56) and last - the $2^{\text {nd }}$ population with $\mathrm{Ab}$ against APMV-1 (1:30.33).

Table 2. Results for the presence of antibodies against APMV-1 and/or H6N2 or three populations birds vaccinated only with APMV-1 strain La Sota, infected only with AIV strain H6N2, infected with AIV strain H6N2 and after 2 days, vaccinated with APMV-1 strain La Sota

\begin{tabular}{|c|c|c|c|c|c|}
\hline \multicolumn{2}{|c|}{ MAT $^{*} \quad$ days $\rightarrow$} & 14 day & 21 day & 28 day & $\begin{array}{l}\text { MAT of birds } \\
\text { from the } \\
\text { population }\end{array}$ \\
\hline \multicolumn{2}{|c|}{$\begin{array}{l}\text { MAT of infected with APMV-1 only (first } \\
\text { population) }\end{array}$} & $1: 44.00$ & $1: 32.00$ & $1: 32.00$ & $1: 36.00$ \\
\hline \multirow{2}{*}{$\begin{array}{l}\text { MAT of infected with AIV } \\
\text { and vaccinated with } \\
\text { APMV-1 } \\
\text { (second population) }\end{array}$} & Test for APMV-1 & $1: 54.40$ & $1: 18.00$ & $1: 26.67$ & $1: 30.33$ \\
\hline & Test for AIV & $1: 53.33$ & $1: 48.00$ & $1: 26.67$ & $1: 42.67$ \\
\hline \multicolumn{2}{|c|}{$\begin{array}{l}\text { MAT of infected with AIV only } \\
\text { (third population) }\end{array}$} & $1: 53.33$ & $1: 26.67$ & $1: 20.67$ & $1: 33.56$ \\
\hline
\end{tabular}

* Mean arithmetic titres of haemagglutinins

\section{DISCUSSION}

AIV and APMV-1 co-infections could occur in birds. The probability is higher when the more common low-pathogenic avian influenza Strains (LPAIV) and low-virulent vaccinal APMV-1 strains are involved $(20,21)$. Coinfections in some avian species (including guinea fowl) are not reported. The experiments with birds compared to chick embryos present the advantage to evaluate the effect of coinfection on affected organs and on immune response $(1,3)$.

In our study, all birds reacted to the vaccinal APMV-1 strain La Sota applied after infection with LPAIV strain H6N2. The response was 
confirmed by the presence of both viruses in birds (detected after reisolation) and the presence of humoral immune response against them.

Surprisingly, our results demonstrated the lack of APMV-1 La Sota reisolates, both in monoand co-infection despite the intranasal and oral administration. Furthermore, the amount and titre of the virus used in our experiment were higher compared to other reported studies. Experiments with chickens, chickens and turkeys, ducks (8-10) inoculated nasally, nasally and ocularly (8) with APMV-1 at a dose of $10^{6} / \mathrm{EID}_{50}$ and $10^{7} / \mathrm{EID}_{50}(8)$ that latter in amount of $0.1 \mathrm{ml}$, always resulted in cloacal reisolates. They were demonstrated in experimental designs comprising independent, simultaneous or later challenge with the virus. The data proved only reduced number of isolates from the cloaca compared to the oropharynx. The results could be explained by the used avian species - guineafowl. The investigations of El-Yuguda et al. $(11,12)$ with guineafowl vaccinated and infected with IBDV and later, vaccinated with a lentogenic APMV1 strain La Sota did not perform any attempts for reisolation, but only evaluated the humoral immune response and pathological changes.

Similar results for reisolation of AIV strain H6N2 from cloacal and oropharyngeal samples in monoinfections or co-infections with APMV-1 La Sota in our experiment with guineafowl were stablished in literature data on chickens and turkeys $(8,10)$. According to the results, there is no effect of the lentogenic strain of APMV-1 on LPAIV replication and viral progeny production.

Our results demonstrated altered dynamics of APMV-1 La Sota virus replication in coinfection with LPAIV strain H6N2 на. It was manifested by reduction by $50 \%$ of the reisolates in oropharyngeal samples 2 days after the challenge with the second virus (APMV-1strain La Sota). All reported previous experiments have demonstrated disturbed replication of the second virus in co-infections in both $\mathrm{CE}$ and chickens $(2,8,10)$. The difference was that in birds, the authors reported a longer period of decline in virus replication manifested with lower number of reisolates and lower viral titres $(8,10)$. Furthermore, Umar et al. (10) found out a shorter mean period of reisolation in days. The probable cause was a transient period when both agents competed for target cells with presence of trypsin or trypsin-like enzymes $(8$, 19, 20), where they propagate. Problems could also occur in the subsequent stages of virus replication and interferon synthesis $(8,21,22)$. They do not permit the replication of the virus that has penetrated second.

In our experiment with co-infection, the number of reisolates of the second virus (vaccinal strain La Sota of APMV-1) increased later. While in monoinfection, the peak of reisolated occurred by the $2^{\text {nd }}-4^{\text {th }}$ day, in coinfected birds it attained the monoinfection peak by the $3^{\text {rd }}-4^{\text {th }}$ day. The reisolation period was more prolonged by 2 days (day 6) vs monoinfection (day 4). A similar finding in LPAIV and lentogenic APMV-1 strains with initial low viral replication and higher and more prolonged virus shedding was described by Costa-Hurtago et al. (8) in chickens and turkeys. The cause is the earlier inoculation with LPAIV, which blocks the receptors of target cells and the immune response readjustment of the body induced by its 5-day presence, which results in lower number of reisolates. For the lentogenic я APMV-1 strain, a favourable time for propagation is the period when the reisolates of the first virus - LPAIV - are reduced. This period matches the beginning of the infection with the second lentogenic APMV-1 virus (day 3-5) when the body has not yet raised an immune defensive response against its antigens. This is confirmed by the fact that later, about the $5^{\text {th }}-6^{\text {th }}$ day of the challenge with the second virus (APMV-1), its reisolates also decreased and disappeared on the $7^{\text {th }}$ day.

Despite the lower replication of the second virus (APMV-1), in the beginning of the coinfection with LPAIV the humoral immune response to both viruses was not reduced. The humoral immune response to both strains was similar to that observed in monoinfections. The same results were communicated by CostaHurtago et al. (8) in chickens and turkeys.

Unlike our study, El-Yuguda et al. $(11,12)$ observed disturbed humoral immune response in guinea fowl against a lentogenic APMV-1 strain in con-infection with vaccinal pathogenic IBDV.

The replication of IBDV is known to occur in the bursa of Fabricius. In young birds, the bursa of Fabricius is the organs where antibodies are produced. LPAIV is not acknowledged to affect the birds of Fabricius during its replication. Being trypsin-dependent viruses, their propagation takes place in organs where trypsin and trypsin-like enzymes are present (lungs and intestines). 


\section{CONCLUSION}

Spontaneous infections with more than a single agent are often seen in birds. They are also observed in cases of a spontaneous monoinfection and application of a live vaccine or vaccination with 2 or more live vaccines. At a global scale, live lentogenic vaccines with different APMV-1 strains are actively and repeatedly applied in birds, and at the same time, other infections, with AIV in particular, could be present. The interest towards APMV-1 and AIV co-infections in birds is also based on the fact that they compete for the same receptors in sensitive target cells. The comparative data obtained in birds with monoinfections and co-infections showed differences from the presence of a second infectious agent. Our experiments with co-infected guineafowl revealed an altered dynamics of virus replication and virus shedding level, while the humoral immune response to both viruses remained unchanged.

\section{The experiments in the publication are} funded by scientific project 1/2016, VMF

\section{REFERENCES}

1. Shortridge, K.F. and King, A.P. Cocultivation of avian orthomyxoviruses and paramyxoviruses in embryonated eggs: implications for surveillance studies. Appl Environ Microbiol., 45 : 463 - 467, 1983.

2. Liu, W., Ding, W., Kong, J., Wang, H., Hu, S., He, H., Zhang, R.and Liu, X. The interference in the virus propagation in chicken embryo and in the HI test between the newcastle disease virus and the H9 subtype influenza virus. Chinese Poultry Science, 7: 3, 2003.

3. Ge, S., Zheng, D., Zhao, Y., Liu, H., Liu, W., Sun, Q., Li, J., Yu, S., Zuo, Y., Han, X., Li, Lin., Yan, L., Wang, Y., Liu, X., and Wang $Z$. Evaluating viral interference between Influenza virus and Newcastle disease virus using real-time reverse transcription-polymerase chain reaction in chicken eggs. Virology Journal, 9 : 128, 2012. DOI: $10.1186 / 1743-422 X-9-128$.

4. Halvorson, D. A. Control of low pathogenicity avian influenza. In: Avian influenza. Edited by Swayne DE.: Blackwell Publishing, Ames Iova, USA: 513-536, 2008.

5. Stipkovits, L., Egyed, L., Palfi, V., Beres, A., Pitlik, E., Somogyi, M., Szathmary, S., \& Denes, B. Effect of low-pathogenicity influenza virus H3N8 infection on Mycoplasma gallisepticum infection of chickens. Avian Pathology, Volume 41, Issue $1: 51$ - 57, 2012.
6. Woolcock, P. R. Avian influenza virus isolation and propagation in chicken eggs. In E. Spackman, (Ed.). Avian Influenza Virus 1sted.: 35-46. Totowa, NJ: Humana Press, 2008.

7. El Zowalaty, M.E., Chander, Y., Redig, P.T., Abd el Latif, H.K., El Sayed. M.A., and Goyal, S, M. Selective isolation of Avian influenza virus (AIV) from cloacal samples containing AIV and Newcastle disease virus. J. Vet. Diagn. Invest., 23 : $330-332,2011$.

8. Costa-Hurtado, M., Afonso, C. L., Miller, P. J., Spackman, E., Kapczynski, D. R., Swayne, D. E., Shepherd, E., Smith, D., Zsak, A. and Pantin-Jackwood, M. Virus interference between H7N2 low pathogenic avian influenza virus and lentogenic Newcastle disease virus in experimental coinfections in chickens and turkeys. Vet. Res. 45 (1) : 1. Published online 2014, Jan 6, 2014, doi: 10.1186/1297-9716-45-1, PMCID: PMC3890543.

9. França, M., Howerth, E. W. , Carter, D., Byas, A., Poulson, R., Afonso, C. L. \& Stallknecht, D. E. Co-infection of mallards with low-virulence Newcastle disease virus and low-pathogenic avian influenza virus. Avian Pathology, 43, 1: 96 - 104, 2014.

10.Umar, S., Azeem, T., Abid, S. A., Mushtaq, A., Aqil, K., Qayyum, M.R., and Rehman, A. Effect of lentogenic Newcastle disease virus (Lasota) on low pathogenic avian influenza vrus (H9N2) infection in fayoumi chicken. Journal of Avian Research, 1 (1): $1-4,2015$.

11.El-Yuguda, A. D, Wachida, N. and Baba, S. S. Interference of Infectious Bursal Diseases (IBD) Virus and Vaccine with the Immune Responses of Guinea Fowls to Newcastle Disease Lasota Vaccination. African Journal of Biomedical Research, Vol. 10 : 189 - 192, 2007.

12.El-Yuguda, A. D., Baba, S. S. and Geidam, Y.A. Specific antibody response of village chickens to single or combined Newcastle disease and infectious bursal disease vaccines. J. Adv. Vet. Anim. Res. 1(1): 16 20, 2014.

13.Zarkov, Iv. Ilian Bochev, Ruth Manvell, Wendey Shell. The First Isolation of Avian Influenza Virus in Bulgaria. Journal of Veterinary Record, 158, 3: 106-107, 2006.

14.Reed, L. J., H. Muench. A simple methods of estimating fifty percent endpoints. Journal of Hygiene, 27: 493-497, 1938.

15.Anonymous. Avian Influenza, Version adopted by the World Assembly of Delegates of the OIE in May 2015, OIE Terrestrial Manual 2015, Chapter 2.3.4: 123, 2015. 
16.Anonymous. Newcastle disease. Version adopted by the World Assembly of Delegates of the OIE in May 2012. OIE Terrestrial Manual, Chapter 2.3.14 : 1 19, 2012.

17.Pawar, S.D., Kale, S.D., Rawankar, A.S., Koratkar, S.S., Raut, C.G., Pande, S.A., Mullick, J., Mishra, A.C. Avian influenza surveillance reveals presence of low pathogenic avian influenza viruses in poultry during 2009-2011 in the West Bengal State. India Virol. Journal, 9: 151, 2012.

18.Roussan, D.A., Haddad, R., Khawaldeh, G. Molecular survey of avian respiratory pathogens in commercial broiler chicken flocks with respiratory diseases in Jordan. Poult. Sci.,87: 444-448. 2008.
19.Rott, R. Molecular basis of infectivity and pathogenicity of myxovirus. Brief review. Arch. Virol, 59: 285-298, 1979.

20.Swayne, D.E., D.A. Halvorson. Influenza. In: Diseases of Poultry. 12th edition. Edited by Saif, Y.M., Glisson, J.R., McDougald, L.R., Nolan, L.K., Swayne, D.E. Blackwell Publishing, Ames, Iowa, USA, 1531842008.

21.Dianzani, F. Viral interference and interferon. Ric. Clin. Lab. 5: 196-2131975.

22.Kimura, Y., Norrby, E., Nagata, I., Ito, Y., Shimokata, K. Homologous interference induced by a temperature-sensitive mutant derived from an HVJ (Sendai virus) carrier culture. J. Gen. Virol. 33: 333-343, 1976. 